ARTICLE

DOI: $10.1038 / s 41467-018-04213-9$

OPEN

\title{
Ambient ammonia synthesis via palladium- catalyzed electrohydrogenation of dinitrogen at low overpotential
}

\author{
Jun Wang ${ }^{1}$, Liang $\mathrm{Yu}^{2}$, Lin $\mathrm{Hu}^{3}$, Gang Chen ${ }^{4}$, Hongliang $\mathrm{Xin}^{2} \&$ Xiaofeng Feng (1) ${ }^{1}$
}

Electrochemical reduction of $\mathrm{N}_{2}$ to $\mathrm{NH}_{3}$ provides an alternative to the Haber-Bosch process for sustainable, distributed production of $\mathrm{NH}_{3}$ when powered by renewable electricity. However, the development of such process has been impeded by the lack of efficient electrocatalysts for $\mathrm{N}_{2}$ reduction. Here we report efficient electroreduction of $\mathrm{N}_{2}$ to $\mathrm{NH}_{3}$ on palladium nanoparticles in phosphate buffer solution under ambient conditions, which exhibits high activity and selectivity with an $\mathrm{NH}_{3}$ yield rate of $\sim 4.5 \mu \mathrm{g} \mathrm{mg}^{-1} \mathrm{Pd}^{-1}$ and a Faradaic efficiency of $8.2 \%$ at $0.1 \mathrm{~V}$ vs. the reversible hydrogen electrode (corresponding to a low overpotential of $56 \mathrm{mV}$ ), outperforming other catalysts including gold and platinum. Density functional theory calculations suggest that the unique activity of palladium originates from its balanced hydrogen evolution activity and the Grotthuss-like hydride transfer mechanism on $\alpha$-palladium hydride that lowers the free energy barrier of $\mathrm{N}_{2}$ hydrogenation to ${ }^{*} \mathrm{~N}_{2} \mathrm{H}$, the rate-limiting step for $\mathrm{NH}_{3}$ electrosynthesis.

\footnotetext{
${ }^{1}$ Department of Physics, University of Central Florida, Orlando, FL 32816, USA. ${ }^{2}$ Department of Chemical Engineering, Virginia Polytechnic Institute and State University, Blacksburg, VA 24061, USA. ${ }^{3}$ Department of Materials Science and Engineering, University of Central Florida, Orlando, FL 32816, USA.

${ }^{4}$ Department of Chemistry, University of Central Florida, Orlando, FL 32816, USA. Correspondence and requests for materials should be addressed to

X.F. (email: Xiaofeng.Feng@ucf.edu) or to H.X. (email: hxin@vt.edu)
} 
$\mathrm{D}$ ue to the limited supply of fossil fuels, there is a critical demand to use renewable energy to drive the chemical processes that have heavily relied on the consumption of fossil fuels ${ }^{1}$. One such energy-intensive chemical process is the Haber-Bosch process ${ }^{2,3}$, which produces $\mathrm{NH}_{3}$ from $\mathrm{N}_{2}$ and $\mathrm{H}_{2}$ using iron-based catalysts under high temperature $\left(350-550^{\circ} \mathrm{C}\right)$ and high pressure $(150-350 \mathrm{~atm}) . \mathrm{NH}_{3}$ is one of the most highly produced inorganic chemicals in the world, because of its vast need in fertilizer production, pharmaceutical production, and many other industrial processes ${ }^{4,5}$. In 2015, around 146 million tons of $\mathrm{NH}_{3}$ was produced globally through the Haber-Bosch process $^{6}$, which consumes $3-5 \%$ of the annual natural gas production worldwide, approximating to $1-2 \%$ of the global annual energy supply ${ }^{2}, 5$. This industrial process is also responsible for $>1 \%$ of the global $\mathrm{CO}_{2}$ emissions ${ }^{2}$. Therefore, it is highly desirable to develop an alternative, efficient process for $\mathrm{NH}_{3}$ synthesis using renewable energy ${ }^{7-11}$, which can simultaneously reduce the $\mathrm{CO}_{2}$ emissions.

One alternative approach to the Haber-Bosch process is to use electrical energy to drive the $\mathrm{NH}_{3}$ synthesis reaction under ambient conditions ${ }^{12-15}$, which can reduce the need for high temperature and pressure, and, thereby lower the energy demand. When powered by electricity from renewable energy sources such as solar and wind, electrochemical synthesis of $\mathrm{NH}_{3}$ from $\mathrm{N}_{2}$ and $\mathrm{H}_{2} \mathrm{O}$ can facilitate sustainable, distributed production of $\mathrm{NH}_{3}$, as well as the storage of renewable energy in $\mathrm{NH}_{3}$ as a carbonneutral liquid fuel ${ }^{16-18}$, owing to its high energy density (4.32 $\left.\mathrm{kWh} \mathrm{L}^{-1}\right)$, high hydrogen content $(17.6 \mathrm{wt} \%)$, and facile liquidation (boiling point: $-33.3^{\circ} \mathrm{C}$ at $1 \mathrm{~atm}$ ). However, the development of the process has been impeded by the lack of efficient electrocatalysts for $\mathrm{N}_{2}$ reduction reaction $\left(\mathrm{N}_{2} \mathrm{RR}\right)$. Although electrochemical synthesis of $\mathrm{NH}_{3}$ has been demonstrated on various materials including $\mathrm{Ru}, \mathrm{Pt}, \mathrm{Au}, \mathrm{Fe}$, and $\mathrm{Ni}^{19-31}$, most of them showed low activity and selectivity (typically, Faradaic efficiency $<1 \%$ ) for $\mathrm{NH}_{3}$ production ${ }^{26-31}$. Therefore, major improvement in $\mathrm{N}_{2} \mathrm{RR}$ catalysts is essential for the development of low-temperature $\mathrm{NH}_{3}$ electrolyzers, which necessitates a better understanding and control of the catalytic materials and the reaction kinetics.

There are two major challenges associated with electrochemical $\mathrm{NH}_{3}$ synthesis in aqueous media ${ }^{32,33}$. From the thermodynamic point of view, the splitting of the strong $\mathrm{N} \equiv \mathrm{N}$ bond requires a reduction potential where the hydrogen evolution reaction (HER) readily occurs, leading to an extremely low Faradaic efficiency for $\mathrm{N}_{2} \mathrm{RR}$ under ambient conditions ${ }^{26-31}$. Therefore, it would be optimal to find a catalytic system that can promote $\mathrm{N}_{2} \mathrm{RR}$ at low overpotentials and suppress the competing HER. From the kinetic perspective, it is suggested that the rate-determining step for $\mathrm{N}_{2} \mathrm{RR}$ is the formation of ${ }^{*} \mathrm{~N}_{2} \mathrm{H}$ through a proton-coupled electron transfer process $\left(\mathrm{H}^{+}+\mathrm{e}^{-}+{ }^{*}+\mathrm{N}_{2} \rightarrow{ }^{*} \mathrm{~N}_{2} \mathrm{H}\right)^{33}, 34$, where ${ }^{*}$ signifies an active site on the catalyst surface. It involves a proton from the electrolyte, an electron transferred from the electrode, and a $\mathrm{N}_{2}$ molecule in the solution. The strong solvent reorganization required for the endergonic charge transfer steps has a low probability of occurrence, leading to the sluggish kinetics. Instead, if the atomic ${ }^{\star} \mathrm{H}$ species can be formed on a catalyst surface and directly react with $\mathrm{N}_{2}$, it may largely accelerate the kinetics to form ${ }^{\star} \mathrm{N}_{2} \mathrm{H}:{ }^{*} \mathrm{H}+\mathrm{N}_{2} \rightarrow{ }^{*} \mathrm{~N}_{2} \mathrm{H}$. Indeed, there have been several investigations of metal hydride complexes for $\mathrm{N}_{2}$ reduction in a homogenous medium ${ }^{35}$, 36. Similarly, $\mathrm{NH}_{3}$ synthesis has been achieved at a low temperature by $\mathrm{LiH}$-mediated $\mathrm{N}_{2}$ transfer and hydrogenation on the transition metal ${ }^{37}$. Therefore, it is imperative to examine such a hydrogenation pathway for the electrochemical $\mathrm{N}_{2} \mathrm{RR}$ in aqueous electrolyte systems under ambient conditions.

Here we report an ambient electrochemical reduction of $\mathrm{N}_{2}$ to $\mathrm{NH}_{3}$ on carbon black-supported Pd nanoparticles (Pd/C), which can form Pd hydrides under certain potentials and promote surface hydrogenation reactions. Operating in a $\mathrm{N}_{2}$-saturated phosphate buffer solution (PBS) electrolyte, the $\mathrm{Pd} / \mathrm{C}$ catalyst enables $\mathrm{NH}_{3}$ production with a yield rate of around $4.5 \mu \mathrm{g} \mathrm{mg}^{-1} \mathrm{Pd}^{-1}$ and a high Faradaic efficiency of $8.2 \%$ at $0.1 \mathrm{~V}$ vs. the reversible hydrogen electrode (RHE), which corresponds to a low overpotential of $56 \mathrm{mV}$. This catalytic performance is enabled by an effective suppression of the HER activity in the neutral PBS electrolyte and the Grotthuss-like hydride transfer mechanism on $\alpha-\mathrm{PdH}$ for $\mathrm{N}_{2}$ hydrogenation. All potentials reported in this study are with respect to the RHE scale.

\section{Results}

Synthesis and characterization of $\mathrm{Pd} / \mathrm{C}$ catalyst. The $\mathrm{Pd} / \mathrm{C}$ catalyst was prepared using polyol reduction method (see Methods section for experimental details). Figure 1a shows a representative transmission electron microscopy (TEM) image of the obtained $\mathrm{Pd} / \mathrm{C}$ catalyst, which suggests that the $\mathrm{Pd}$ nanoparticles are homogeneously dispersed on the carbon black. The nanoparticle sizes have a narrow distribution between 4 and 9 $\mathrm{nm}$, with an average size of around $6 \mathrm{~nm}$ (see the inset of Fig. 1a). A high-resolution TEM image in Fig. 1b shows the atomic lattice fringes of the particles with lattice plane spacings determined to be $0.225 \mathrm{~nm}$, corresponding to the (111) lattice spacing of Pd. An $\mathrm{X}$-ray diffraction (XRD) pattern of the $\mathrm{Pd} / \mathrm{C}$ catalyst is shown in Fig. $1 c$, in which the peaks with $2 \theta$ values of $40.1^{\circ}, 46.6^{\circ}, 68.1^{\circ}$, $82.1^{\circ}$, and $86.6^{\circ}$ can be indexed to the diffraction from the (111), (200), (220), (311), and (222) lattice planes of Pd, respectively (PDF\#65-2867). X-ray photoelectron spectroscopy (XPS) was used to examine the elemental composition of the $\mathrm{Pd} / \mathrm{C}$ catalyst. As shown in Fig. 1d, only Pd, C, and O were observed in the survey spectrum, where the binding energies of 335.4 and 340.9 $\mathrm{eV}$ correspond to the $3 \mathrm{~d}_{5 / 2}$ and $3 \mathrm{~d}_{3 / 2}$ levels of metallic $\mathrm{Pd}^{0}$. Of note, no $\mathrm{N}$ species were observed within the detection limit of the XPS ( 0.1 atomic percent), as shown in Supplementary Fig. 1.

Electroreduction of $\mathrm{N}_{2}$ to $\mathrm{NH}_{3}$ on the $\mathrm{Pd} / \mathrm{C}$ catalyst. The electrochemical measurements were performed using a gas-tight two-compartment electrochemical cell separated by a piece of Nafion 115 membrane (Supplementary Fig. 2). A piece of Pt gauze and $\mathrm{Ag} / \mathrm{AgCl}$ electrode (filled with saturated $\mathrm{KCl}$ solution) were used as counter electrode and reference electrode, respectively. The working electrode was prepared by dispersing the $\mathrm{Pd} /$ C catalyst on a carbon paper or a glassy carbon substrate, as specified below. $\mathrm{N}_{2}$ gas was delivered into the cathodic compartment by $\mathrm{N}_{2}$ gas bubbling. The $\mathrm{N}_{2} \mathrm{RR}$ activities of the electrodes were evaluated using controlled potential electrolysis with $\mathrm{N}_{2}$-saturated electrolyte for $3 \mathrm{~h}$. All potentials were iRcompensated and converted to the RHE scale via calibration (Supplementary Fig. 3). The gas-phase product $\left(\mathrm{H}_{2}\right)$ was quantified by periodic gas chromatography of the headspace. The produced $\mathrm{NH}_{3}$ in the solution phase was quantified at the end of each electrolysis using the calibration curves established by the indophenol blue method ${ }^{38}$ (Supplementary Fig. 4). Another possible solution-phase product, $\mathrm{N}_{2} \mathrm{H}_{4}$, was also determined using a spectrophotometric method developed by Watt and Chrisp ${ }^{39}$ (Supplementary Fig. 5), whereas no $\mathrm{N}_{2} \mathrm{H}_{4}$ was detected in our studies within the detection limit of the method.

To boost the selectivity for $\mathrm{N}_{2} \mathrm{RR}$, we need to find an electrolyte that can effectively suppress the competing HER. We compared the HER activities of the $\mathrm{Pd} / \mathrm{C}$ catalyst in three Ar-saturated electrolytes: $0.05 \mathrm{M} \mathrm{H}_{2} \mathrm{SO}_{4}(\mathrm{pH}=1.2), 0.1 \mathrm{M} \mathrm{PBS}(\mathrm{pH}=7.2)$, and $0.1 \mathrm{M} \mathrm{NaOH}(\mathrm{pH}=12.9)$. Linear sweep voltammograms (LSV) of the $\mathrm{Pd} / \mathrm{C}$ catalyst in the three electrolytes show that the current densities measured in $\mathrm{H}_{2} \mathrm{SO}_{4}$ and $\mathrm{NaOH}$ are both several times 
a
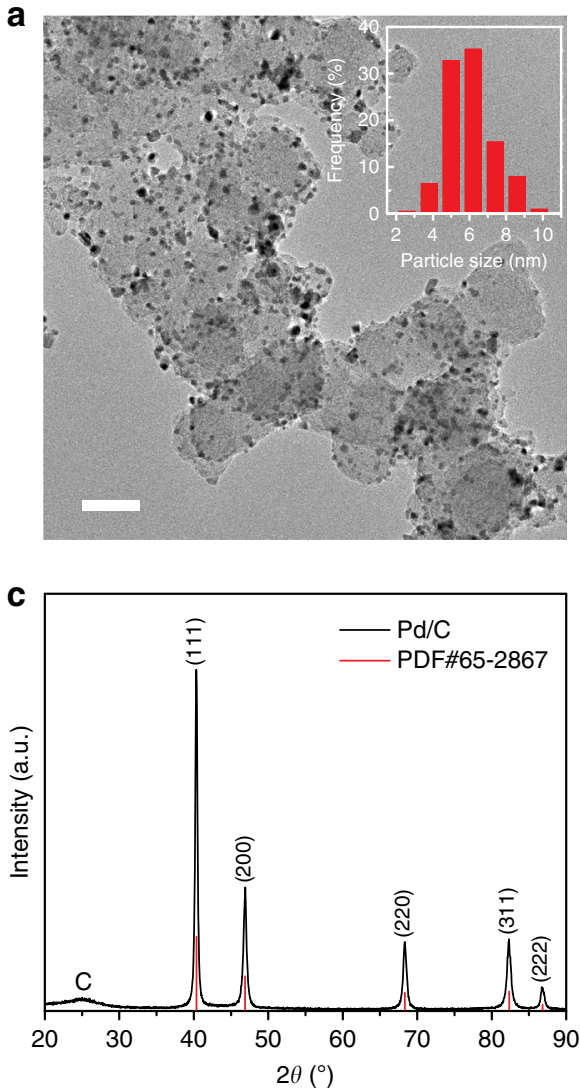

b
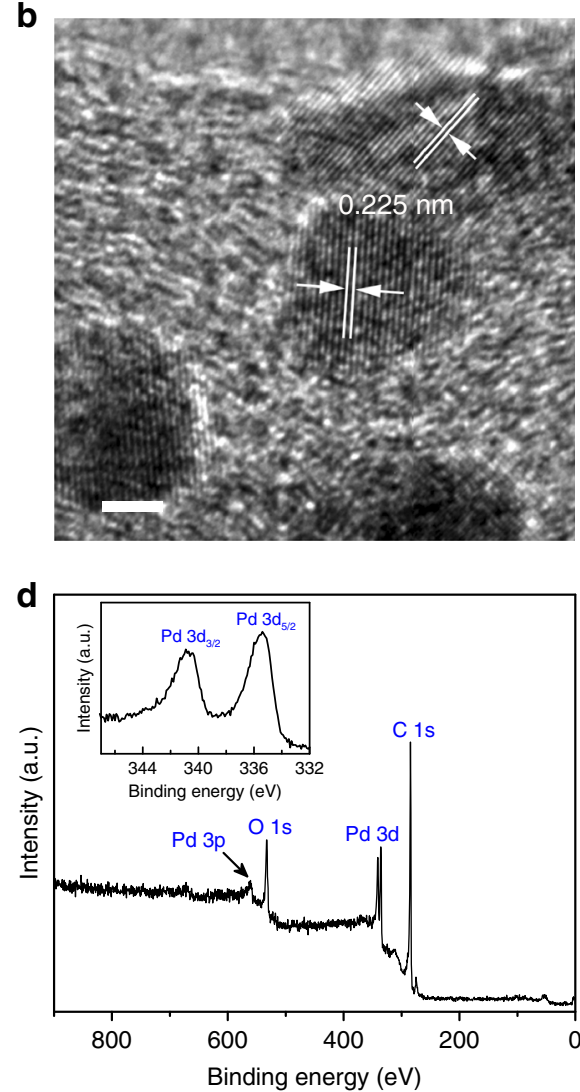

Fig. 1 Structural and compositional characterizations of the Pd/C catalyst. a TEM and $\mathbf{b}$ high-resolution TEM images of the Pd/C catalyst. Inset a: particle size distribution. Scale bars, a $50 \mathrm{~nm} ; \mathbf{b} 2 \mathrm{~nm}$. c XRD pattern and d XPS survey spectrum of the Pd/C catalyst. Inset $\mathbf{d}$ : high-resolution XPS spectrum of Pd 3d peaks

higher than those in PBS in a wide potential range (see Fig. 2a and Supplementary Fig. 6a), indicating an effective suppression of the HER activity in the neutral PBS electrolyte. The less favorable kinetics of HER in PBS is because of its higher barrier for massand charge-transfer ${ }^{40}$, as evidenced by the electrochemical impedance spectra in Supplementary Fig. 6b. Similarly, the controlled potential electrolysis in $\mathrm{N}_{2}$-saturated PBS at $-0.05 \mathrm{~V}$ vs. RHE produces a current density of about $0.3 \mathrm{~mA} \mathrm{~cm}^{-2}$ (Fig. 2b), which is much lower than that in $\mathrm{H}_{2} \mathrm{SO}_{4}(\sim 8 \mathrm{~mA} \mathrm{~cm}$ $\left.{ }^{-2}\right)$ and $\mathrm{NaOH}\left(\sim 3.5 \mathrm{~mA} \mathrm{~cm}^{-2}\right)$. However, the $\mathrm{NH}_{3}$ yield rate in PBS reaches $4.9 \mu \mathrm{g} \mathrm{mg}^{-1} \mathrm{Pd}^{-1}$ (Fig. 2c), which is around two times of that in $\mathrm{H}_{2} \mathrm{SO}_{4}\left(2.5 \mu \mathrm{g} \mathrm{mg}^{-1}{ }_{\mathrm{Pd}} \mathrm{h}^{-1}\right)$ and that in $\mathrm{NaOH}$ $\left(2.1 \mu \mathrm{g} \mathrm{mg}^{-1} \mathrm{Pd}^{-1}\right)$. More strikingly, a Faradaic efficiency of $2.4 \%$ is achieved in PBS, whereas both $\mathrm{H}_{2} \mathrm{SO}_{4}$ and $\mathrm{NaOH}$ electrolytes give rise to a Faradaic efficiency lower than $0.1 \%$. These results clearly indicate that PBS is a promising electrolyte for electrochemical $\mathrm{N}_{2} \mathrm{RR}$ due to its effective suppression of the HER activity. Therefore, all the following $\mathrm{N}_{2} \mathrm{RR}$ experiments were performed with $0.1 \mathrm{M}$ PBS electrolyte.

Subsequently, the activities of the Pd/C catalyst for $\mathrm{N}_{2} \mathrm{RR}$ were systematically investigated in $\mathrm{N}_{2}$-saturated $\mathrm{PBS}$ at various potentials with separately prepared electrodes. As shown in Fig. $2 \mathrm{~d}$, the total current density increases from $\sim 0.05$ to more than $1.2 \mathrm{~mA} \mathrm{~cm}^{-2}$, as the potential shifts from 0.1 to $-0.2 \mathrm{~V}$. Interestingly, the $\mathrm{NH}_{3}$ yield rate remains similar within this potential range, fluctuating around $4.5 \mu \mathrm{g} \mathrm{mg}^{-1} \mathrm{Pd}^{-1}$ (Fig. 2e). Strikingly, the Faradaic efficiency for $\mathrm{NH}_{3}$ production reaches a maximum value of $8.2 \%$ at $0.1 \mathrm{~V}$, which corresponds to a low overpotential of $56 \mathrm{mV}$, given the equilibrium potential of 0.156 $\mathrm{V}$ for $\mathrm{N}_{2}$ reduction to $\mathrm{NH}_{3}$ under our experimental conditions (see Methods section for the calculations). The Faradaic efficiency decreases gradually at more negative potentials, which is mainly caused by the rapid rising of the HER activity (Supplementary Fig. 7). To the best of our knowledge, the Pd/C catalyst achieves an $\mathrm{NH}_{3}$ yield rate and Faradaic efficiency that are comparable to the recently reported catalysts for $\mathrm{N}_{2} \mathrm{RR}$ under ambient conditions (Supplementary Table 1), but uses an overpotential lower by at least $300 \mathrm{mV}$, making it one of the most active and selective electrocatalysts for ambient $\mathrm{NH}_{3}$ synthesis.

In addition, we have carefully examined the $\mathrm{N}$ source of the produced $\mathrm{NH}_{3}$. First, control experiments with Ar-saturated electrolyte or without $\mathrm{Pd}$ catalyst were performed. As shown in Fig. $2 \mathrm{f}$, no apparent $\mathrm{NH}_{3}$ was detected using the indophenol blue method when the bubbled $\mathrm{N}_{2}$ gas was replaced by Ar or when a carbon paper electrode without $\mathrm{Pd}$ was used, indicating that the $\mathrm{NH}_{3}$ was produced by $\mathrm{N}_{2}$ reduction in the presence of Pd catalyst. Furthermore, ${ }^{15} \mathrm{~N}$ isotopic labeling experiment was performed as an alternative method to verify the $\mathrm{N}$ source of the produced $\mathrm{NH}_{3}$ in $0.1 \mathrm{M}$ PBS electrolyte. A triplet coupling for ${ }^{14} \mathrm{NH}_{4}{ }^{+}$and a doublet coupling for ${ }^{15} \mathrm{NH}_{4}{ }^{+}$in the ${ }^{1} \mathrm{H}$ nuclear magnetic resonance ( ${ }^{1} \mathrm{H}$ NMR) spectra are used to distinguish them ${ }^{25}$. As shown in Supplementary Fig. 8, only ${ }^{15} \mathrm{NH}_{4}{ }^{+}$was observed in the electrolyte when ${ }^{15} \mathrm{~N}_{2}$ was supplied as the feeding gas, and no $\mathrm{NH}_{4}{ }^{+}$was detected when $\mathrm{Ar}$ was supplied, which are consistent with the control experiments and confirm that the $\mathrm{NH}_{3}$ was produced by Pd-catalyzed electroreduction of $\mathrm{N}_{2}$.

The stability of the Pd/C catalyst for electrochemical $\mathrm{N}_{2} \mathrm{RR}$ was assessed by consecutive recycling electrolysis at $-0.05 \mathrm{~V}$ vs. RHE. After five consecutive cycles, only a slight decline in the total current density was observed, as shown in Supplementary Fig. 9. However, the $\mathrm{NH}_{3}$ yield rate and Faradaic efficiency decreased to $2.4 \mu \mathrm{g} \mathrm{mg}^{-1}{ }_{\mathrm{Pd}} \mathrm{h}^{-1}$ and $1.2 \%$ after five cycles, indicating a loss of 

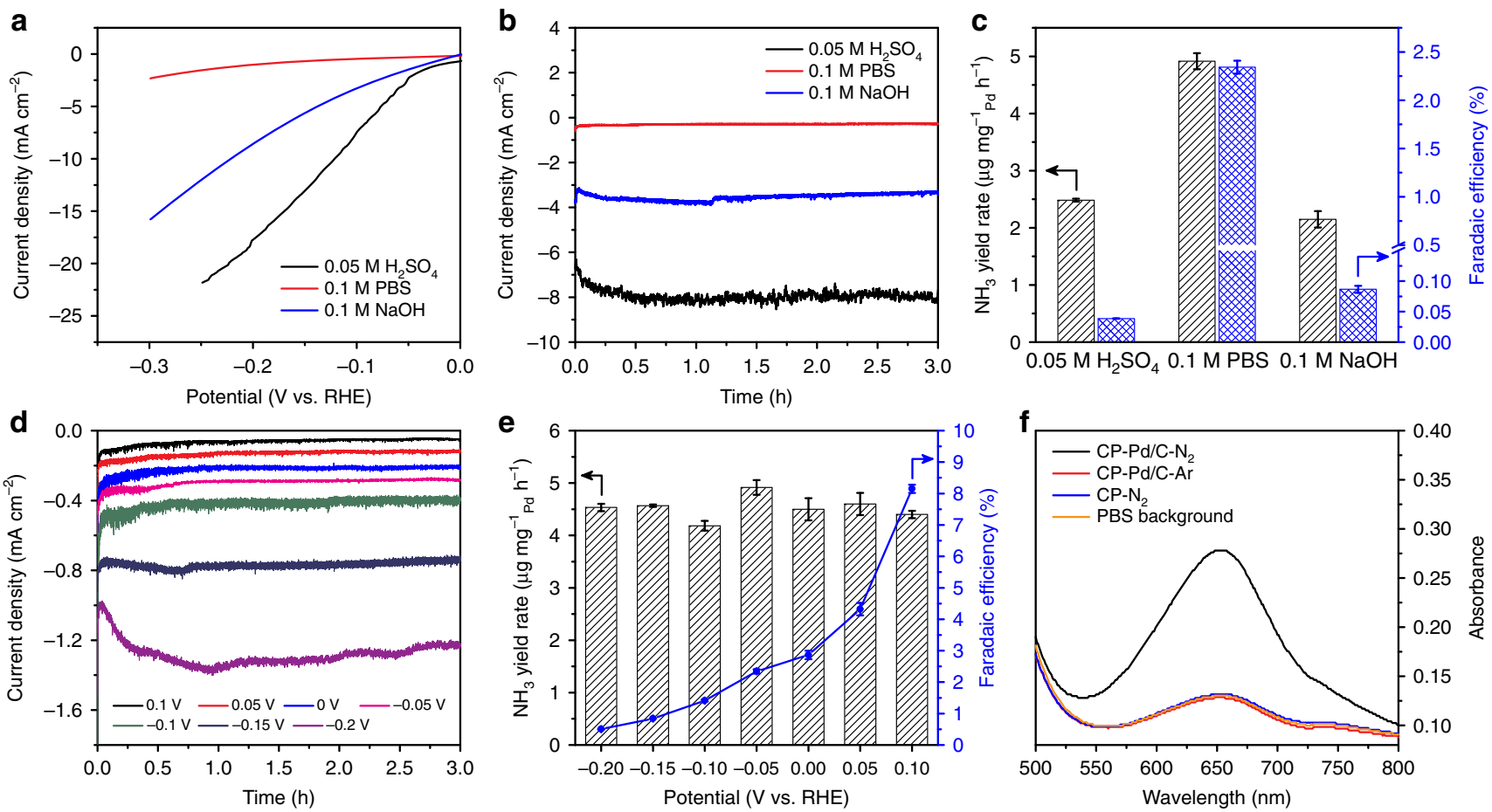

Fig. 2 Electroreduction of $\mathrm{N}_{2}$ to $\mathrm{NH}_{3}$ on the $\mathrm{Pd} / \mathrm{C}$ catalyst. a Linear sweep voltammetric curves of the $\mathrm{Pd} / \mathrm{C}$ catalyst on the glassy-carbon support measured in the three Ar-saturated electrolytes. b Chronoamperometric curves of the $\mathrm{Pd} / \mathrm{C}$ catalyst on the carbon-paper support measured at $-0.05 \mathrm{~V}$ vs. $\mathrm{RHE}$ in the three $\mathrm{N}_{2}$-saturated electrolytes, and c corresponding $\mathrm{NH}_{3}$ yield rates and Faradaic efficiencies in the three electrolytes. $\mathbf{d}$ Chronoamperometric curves of the $\mathrm{Pd} / \mathrm{C}$ catalyst on the carbon-paper support in $\mathrm{N}_{2}$-saturated $0.1 \mathrm{M}$ PBS at various potentials, and e corresponding $\mathrm{NH}_{3}$ yield rates and Faradaic efficiencies at the potentials. The error bars correspond to the standard deviations of measurements over three separately prepared samples under the same conditions. $\mathbf{f}$ UV-vis absorption spectra of the electrolytes after electrolysis at $-0.05 \mathrm{~V}$ vs. $\mathrm{RHE}$ for $3 \mathrm{~h}$ under different conditions. No apparent $\mathrm{NH}_{3}$ was detected for the control experiments with $\mathrm{Ar}$-saturated electrolyte (CP-Pd/C-Ar) or without Pd catalyst (CP- $\left.\mathrm{N}_{2}\right)$, indicating that $\mathrm{NH}_{3}$ was produced by Pd-catalyzed electroreduction of $\mathrm{N}_{2}$

the $\mathrm{N}_{2} \mathrm{RR}$ activity by $50 \%$ after the $15 \mathrm{~h}$ operation. The decrease in the $\mathrm{N}_{2} \mathrm{RR}$ activity is due to the loss of active Pd surface area caused by the aggregation of $\mathrm{Pd}$ nanoparticles on the carbon support, as evidenced by the TEM images of the $\mathrm{Pd} / \mathrm{C}$ catalyst after the recycling test (Supplementary Fig. 9). Further improvement in the dispersion of Pd nanoparticles on the support and interaction between them will be beneficial for the long-term durability of the catalyst.

\section{Discussion}

The $\mathrm{Pd} / \mathrm{C}$ catalyst exhibits high activity and selectivity for the $\mathrm{N}_{2} \mathrm{RR}$ at a low overpotential of $56 \mathrm{mV}$. To explore the underlying mechanism and to see whether it is exclusive to $\mathrm{Pd}$, we prepared $\mathrm{Au} / \mathrm{C}$ and $\mathrm{Pt} / \mathrm{C}$ catalysts with identical metal loading using the same method, and compared their $\mathrm{N}_{2} \mathrm{RR}$ catalytic performance with that of the $\mathrm{Pd} / \mathrm{C}$ catalyst (Fig. 3). The structural and compositional characterizations of the $\mathrm{Au} / \mathrm{C}$ and $\mathrm{Pt} / \mathrm{C}$ catalysts, including TEM, XRD, and XPS (Supplementary Fig. 10), confirm the successful synthesis of the metal nanoparticles with similar sizes as that of the Pd/C catalyst. At $-0.05 \mathrm{~V}$ vs. RHE, the $\mathrm{Au} / \mathrm{C}$ catalyst exhibits a current density $\left(<0.04 \mathrm{~mA} \mathrm{~cm}^{-2}\right)$ much lower than that of the $\mathrm{Pd} / \mathrm{C}$ catalyst, whereas the $\mathrm{Pt} / \mathrm{C}$ catalyst shows a slightly higher current density (see inset of Fig. 3). Both the $\mathrm{Au} / \mathrm{C}$ and $\mathrm{Pt} / \mathrm{C}$ catalysts produce $\mathrm{NH}_{3}$ at a rate of about $0.3 \mu \mathrm{gmg}$ ${ }^{-1}$ metal $\mathrm{h}^{-1}$, which is lower than that of the $\mathrm{Pd} / \mathrm{C}$ catalyst by more than one order of magnitude. The $\mathrm{Au} / \mathrm{C}$ catalyst achieves a Faradaic efficiency of $1.2 \%$ for $\mathrm{N}_{2} \mathrm{RR}$, due to its low activity for the HER. In contrast, the Faradaic efficiency for $\mathrm{N}_{2} \mathrm{RR}$ on the $\mathrm{Pt} / \mathrm{C}$ catalyst is only $0.2 \%$, much lower than that of the $\mathrm{Au} / \mathrm{C}$ catalyst, because $\mathrm{Pt}$ is intrinsically the most active catalyst for HER

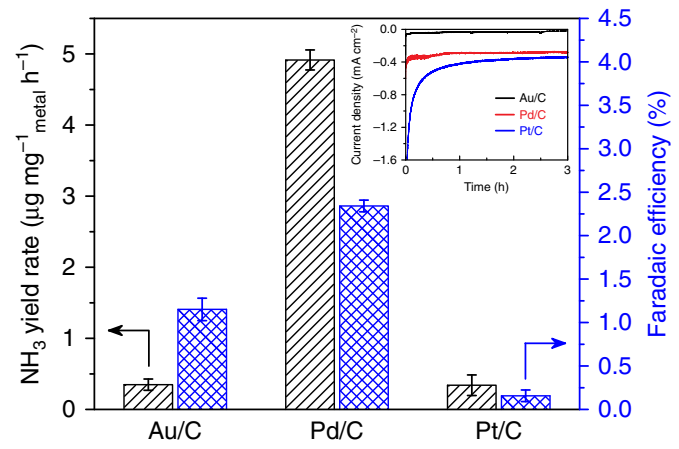

Fig. 3 Comparison of the $\mathrm{Pd} / \mathrm{C}$ catalyst with $\mathrm{Au} / \mathrm{C}$ and $\mathrm{Pt} / \mathrm{C}$ catalysts for $\mathrm{N}_{2} \mathrm{RR}$. $\mathrm{NH}_{3}$ yield rates and Faradaic efficiencies of the $\mathrm{Au} / \mathrm{C}, \mathrm{Pd} / \mathrm{C}$, and Pt/ $C$ catalysts on the carbon-paper support measured in $\mathrm{N}_{2}$-saturated $0.1 \mathrm{M}$ PBS electrolyte at $-0.05 \mathrm{~V}$ vs. RHE. The error bars correspond to the standard deviations of measurements over three separately prepared samples under the same conditions. Inset: chronoamperometric curves obtained for each catalyst

(Supplementary Fig. 11). In comparison, such a significant difference in both $\mathrm{N}_{2} \mathrm{RR}$ activity and selectivity clearly indicates that $\mathrm{Pd}$ is a unique catalyst for $\mathrm{N}_{2} \mathrm{RR}$. Actually, $\mathrm{Pd}$ can readily absorb $\mathrm{H}$ atoms in its lattice, forming $\mathrm{Pd}$ hydrides under operating conditions ${ }^{41}$. The cathodic current observed at 0.10 and $0.05 \mathrm{~V}$ is similar to the data in a previous study ${ }^{42}$, and the unaccounted current at the two potentials (see Supplementary Fig. 7b) may be similarly attributed to the dynamic hydrogen adsorption and absorption on $\mathrm{Pd}^{42}$, in addition to the capacitance of the carbon 
support. It has been reported that Pd catalyzes the electroreduction of $\mathrm{CO}_{2}$ to formate with high activity and selectivity at low overpotentials ${ }^{43}, 44$, and both experimental and computational studies have confirmed that it is attributed to a hydrogenation mechanism through in situ formed $\mathrm{PdH}_{\mathrm{x}}$ phase ${ }^{45}$. Interestingly, a recent study of $\mathrm{N}_{2} \mathrm{RR}$ on commercial $\mathrm{Pd} / \mathrm{C}$ catalysts in acidic and alkaline electrolytes showed Faradaic efficiencies lower than $0.1 \%$ at $-0.2 \mathrm{~V}$ vs. $\mathrm{RHE}^{31}$, which are consistent with our results under similar conditions (Fig. 2c), and highlight the critical roles of the HER suppression in PBS and the hydrogenation via hydride transfer pathway at low overpotentials (vide infra).

To understand the unique activity of $\mathrm{N}_{2} \mathrm{RR}$ on $\mathrm{Pd} / \mathrm{C}$, we performed density functional theory (DFT) calculations for the energetics of HER and $\mathrm{N}_{2} \mathrm{RR}$ steps on the (211) surfaces of $\mathrm{Au}, \mathrm{Pt}$, and Pd hydride (see Supplementary Note 1 for the computational details). As employed previously, the undercoordinated step atoms are assumed to be the catalytic site for activating the $\mathrm{N} \equiv \mathrm{N}$ bond ${ }^{4}$. For Pd, we have two subsurface ${ }^{\star} \mathrm{H}\left({ }^{\star} \mathrm{H}_{\text {sub }}\right)$ at the octahedral sites underneath the Pd edge atoms to simulate the $\alpha$ phase Pd hydride $(\alpha-\mathrm{PdH})$, which is the stable phase under operating potentials ${ }^{45}$. According to the differential adsorption free energies of ${ }^{\star} \mathrm{H}$ on the (211) surfaces (Supplementary Fig. 12), we adopted models with $2 / 3$ monolayer of ${ }^{*} \mathrm{H}$ for $\alpha$ - $\mathrm{PdH}$ and $\mathrm{Pt}$, on which the step/terrace sites are occupied by ${ }^{*} \mathrm{H}$ and the bottom-of-the-edge sites are free, while a clean surface for $\mathrm{Au}$ was used (geometric structures shown in Fig. 4). In the inset of Fig. 4, we can see that the HER on Pt is facile with the free formation energy of ${ }^{\star} \mathrm{H}$ close to zero ${ }^{47}$. In contrast, the process is limited by ${ }^{*} \mathrm{H}$ desorption on $\alpha-\mathrm{PdH}$ and by ${ }^{*} \mathrm{H}$ adsorption on $\mathrm{Au}$. Interestingly, the free energy cost in creating a ${ }^{*} \mathrm{H}$ vacancy $\left({ }^{\star} \mathrm{H}-\mathrm{v}\right)$ necessary for $\mathrm{N}_{2}$ collision at step sites is much lower on $\alpha-\mathrm{PdH}(0.18 \mathrm{eV})$ than that on Pt $(0.41 \mathrm{eV})$. Furthermore, the

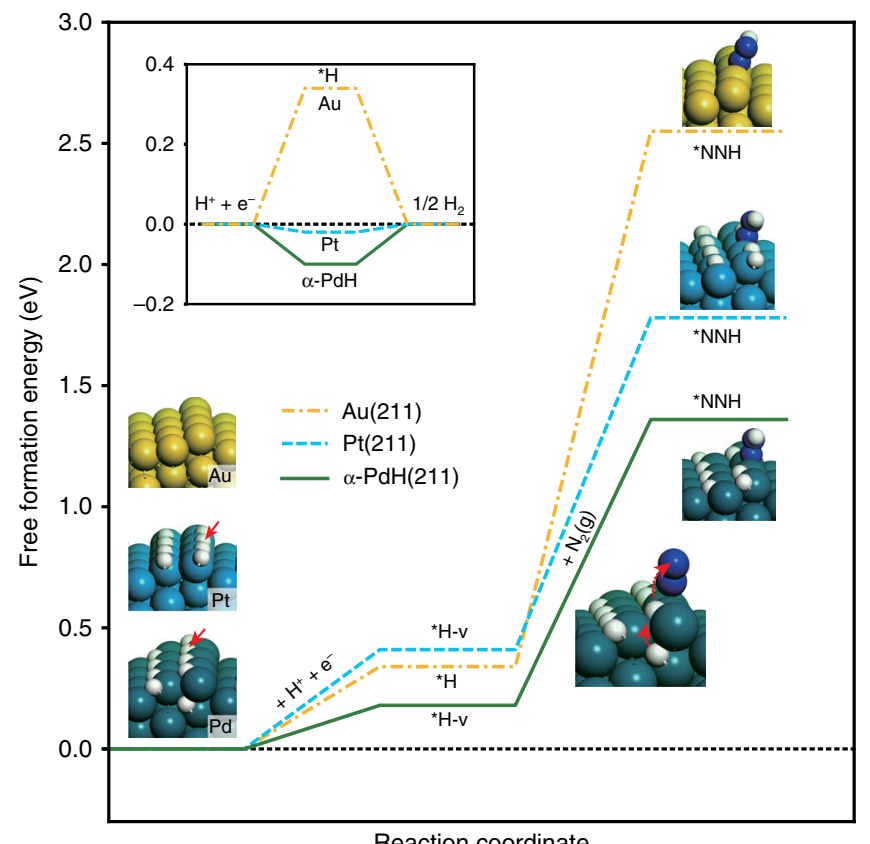

Fig. 4 Computational studies. DFT-calculated free energy pathways of HER (inset) and the relevant steps of $\mathrm{N}_{2} \mathrm{RR}$ on the (211) surfaces of $\mathrm{Au}, \mathrm{Pt}$, and $\alpha-\mathrm{PdH}$ at surface potential of $\mathrm{O} \mathrm{V}$ vs. RHE under $298.15 \mathrm{~K}$ (atomic

structures shown in the insets). The first step denotes the formation of ${ }^{*} \mathrm{H}$ on the Au surface and ${ }^{*} \mathrm{H}$ vacancy $\left({ }^{*} \mathrm{H}-\mathrm{v}\right)$ on $\mathrm{Pt}$ and $\alpha-\mathrm{PdH}$ step sites. The second step is the direct surface hydrogenation of $\mathrm{N}_{2}(\mathrm{~g})$ forming ${ }^{\star} \mathrm{N}_{2} \mathrm{H}$ on $\mathrm{Au}$ and $\mathrm{Pt}$, and the Grotthuss-like hydride transfer pathway on $\alpha-\mathrm{PdH}$ hydrogenation of $\mathrm{N}_{2}$ by a surface ${ }^{*} \mathrm{H}$ to form ${ }^{\star} \mathrm{N}_{2} \mathrm{H}$ on a-PdH $(1.18 \mathrm{eV})$ is thermodynamically more favorable than that on $\mathrm{Pt}$ $(1.37 \mathrm{eV})$ and $\mathrm{Au}(2.21 \mathrm{eV})$. On $\mathrm{a}-\mathrm{PdH}$, the surface hydrogenation is accompanied by the transfer of ${ }^{\star} \mathrm{H}_{\text {sub }}$ to the surface site, analogous to the Grotthuss-like proton-hopping mechanism in a water network ${ }^{48}$. The reaction-free energy of $\mathrm{N}_{2}$ hydrogenation on Pd without the hydride transfer is less favorable by $0.3 \mathrm{eV}$ (see Supplementary Fig. 13 for a direct comparison). The nature of this rate-determining step, i.e., surface chemical hydrogenation instead of the proton-coupled electron transfer, supports the observed weak potential dependence of the $\mathrm{NH}_{3}$ yield rate at low overpotentials. DFT-calculated free energies of hydrogenation of $\mathrm{N}_{2}$ vs. hydrogen evolution across metal surfaces (Au, Pt, and a-PdH) rationalize the activity and selectivity trends in Fig. 3.

In summary, we have discovered an efficient electrohydrogenation of $\mathrm{N}_{2}$ to $\mathrm{NH}_{3}$ on $\mathrm{Pd} / \mathrm{C}$ catalyst at an overpotential as low as $56 \mathrm{mV}$ for the electrochemical $\mathrm{NH}_{3}$ synthesis under ambient conditions. The $\mathrm{Pd} / \mathrm{C}$ catalyst exhibits high activity and selectivity for $\mathrm{N}_{2} \mathrm{RR}$ in a PBS electrolyte, achieving an $\mathrm{NH}_{3}$ yield rate of about $4.5 \mu \mathrm{g} \mathrm{mg}^{-1}{ }_{\mathrm{Pd}} \mathrm{h}^{-1}$ and a Faradaic efficiency of $8.2 \%$ at $0.1 \mathrm{~V}$ vs. RHE. Comparative experiments indicate an effective suppression of the HER in the neutral PBS electrolyte, and a significantly higher $\mathrm{N}_{2} \mathrm{RR}$ activity of Pd than other catalysts including Au and Pt. The DFT calculations suggest that the in situ formed $a-\mathrm{PdH}$ allows the activation of $\mathrm{N}_{2}$ via a Grotthuss-like hydride transfer pathway that is thermodynamically more favorable than direct surface hydrogenation or proton-coupled electron transfer steps. Our findings open up an avenue to develop efficient electrocatalysts for not only the electroreduction of $\mathrm{N}_{2}$ to $\mathrm{NH}_{3}$, but also other challenging electrocatalytic reactions for renewable energy conversions.

\section{Methods}

Synthesis of carbon black-supported metal catalysts. The $\mathrm{Pd} / \mathrm{C}$ catalyst was synthesized using polyol reduction method. First, the Pd precursor $\left(\mathrm{K}_{2} \mathrm{PdCl}_{4}\right)$ solution was prepared by dissolving $\mathrm{PdCl}_{2}$ in water in the presence of $\mathrm{KCl}$. Typically, $70 \mathrm{mg}$ of carbon black was dispersed in $100 \mathrm{~mL}$ of ethylene glycol, followed by sonication for $30 \mathrm{~min}$. Then, $5 \mathrm{~mL}$ of $\mathrm{K}_{2} \mathrm{PdCl}_{4}$ solution $\left(\mathrm{Pd} 6 \mathrm{mg} \mathrm{mL}^{-1}\right.$ ) was added into the mixture. After stirring for another $30 \mathrm{~min}$, the mixture was heated to $130^{\circ} \mathrm{C}$ and kept at this temperature for $2 \mathrm{~h}$. The catalyst slurry was filtered and washed with water. The resulting $\mathrm{Pd} / \mathrm{C}$ catalyst was dried at $60^{\circ} \mathrm{C}$ overnight, with a Pd loading of $30 \mathrm{wt} \%$. Comparative samples of $\mathrm{Au} / \mathrm{C}$ and $\mathrm{Pt} / \mathrm{C}$ catalysts with a metal loading of $30 \mathrm{wt} \%$ were prepared using the same procedure, except with different metal precursors.

Physical characterizations. TEM images were acquired using a FEI Tecnai F30 Transmission Electron Microscope, with a field emission gun operated at $200 \mathrm{kV}$. The XRD pattern was collected using a PANalytical Empyrean diffractometer, with a $1.8 \mathrm{KW}$ copper X-ray tube. XPS was performed using a Physical Electronics 5400 ESCA photoelectron spectrometer. Gas products were analyzed by a gas chromatograph (SRI Multiple Gas Analyzer \#5) equipped with molecular sieve $5 \mathrm{~A}$ and HayeSep D columns, with Ar as the carrier gas.

Preparations of the working electrodes. First, $8 \mathrm{mg}$ of carbon black-supported metal catalyst was dispersed in diluted Nafion alcohol solution containing $1.5 \mathrm{~mL}$ ethanol and $60 \mu \mathrm{L}$ Nafion, which formed a homogeneous suspension after sonication for $1 \mathrm{~h}$. Two types of substrates were used to prepare electrodes in this study: one was carbon paper, and the other was glassy carbon. The carbon-paper electrodes were prepared by drop-casting the suspension on a piece of carbon paper $\left(1 \times 1 \mathrm{~cm}^{2}\right)$, with a total mass loading of $1 \mathrm{mg}$ (of which $30 \mathrm{wt} \%$ is $\mathrm{Pd}$ ), which were used for all controlled potential electrolyses. The glassy-carbon electrodes were prepared by drop-casting the suspension on a round glassy carbon (diameter $=3$ $\mathrm{mm}$ ), with a total mass loading of $0.435 \mathrm{mg} \mathrm{cm}^{-2}$ (of which $30 \mathrm{wt} \%$ is $\mathrm{Pd}$ ), which were used for all linear sweep voltammetry measurements, except Supplementary Fig. 6a.

Electrochemical measurements. Prior to $\mathrm{N}_{2} \mathrm{RR}$ tests, Nafion 115 membranes were heat-treated in $5 \% \mathrm{H}_{2} \mathrm{O}_{2}, 0.5 \mathrm{M} \mathrm{H}_{2} \mathrm{SO}_{4}$, and water for $1 \mathrm{~h}$, respectively. After being rinsed in water thoroughly, the membranes were immersed in deionized water for future use. Electrochemical measurements were performed using a $\mathrm{CH}$ Instruments 760E Potentiostat, with a gas-tight two-compartment electrochemical cell separated by a piece of Nafion 115 membrane at room temperature 
(Supplementary Fig. 2). A piece of $\mathrm{Pt}$ gauze and $\mathrm{Ag} / \mathrm{AgCl} /$ sat. $\mathrm{KCl}$ were used as counter electrode and reference electrode, respectively. The linear sweep voltammetry was scanned at a rate of $5 \mathrm{mV} \mathrm{s}^{-1}$. The $\mathrm{N}_{2} \mathrm{RR}$ activity of an electrode was evaluated using controlled potential electrolysis in an electrolyte for $3 \mathrm{~h}$ at room temperature ( 293 K). Prior to each electrolysis, the electrolyte was presaturated with $\mathrm{N}_{2}$ by $\mathrm{N}_{2}$ gas bubbling for $30 \mathrm{~min}$. During each electrolysis, the electrolyte was continuously bubbled with $\mathrm{N}_{2}$ at a flow rate of $10 \mathrm{sccm}$, and was agitated with a stirring bar at a stirring rate of $\sim 800 \mathrm{rpm}$. No in-line acid trap was used to capture $\mathrm{NH}_{3}$ that might escape from the electrolyte in our study, as no apparent $\mathrm{NH}_{3}$ was detected in the acid trap under our experimental conditions. The applied potentials were iR-compensated, and the reported current densities were normalized to geometric surface areas.

Calibration of the reference electrodes. All potentials in this study were converted to the RHE scale via calibration (Supplementary Fig. 3). The calibration was performed using Pt gauze as both working electrode and counter electrode in $\mathrm{H}_{2}-$ saturated electrolyte. Cyclic voltammograms were acquired at a scan rate of $1 \mathrm{mV} \mathrm{s}$

${ }^{-1}$. The two potentials at which the current equaled zero were averaged and used as the thermodynamic potential for the hydrogen electrode reactions.

Ammonia quantification. The produced $\mathrm{NH}_{3}$ was quantitatively determined using the indophenol blue method ${ }^{38}$. Typically, $2 \mathrm{~mL}$ of the sample solution was first pipetted from the post-electrolysis electrolyte. Afterwards, $2 \mathrm{~mL}$ of a $1 \mathrm{M} \mathrm{NaOH}$ solution containing salicylic acid (5 $\mathrm{wt} \%)$ and sodium citrate $(5 \mathrm{wt} \%)$ was added, and $1 \mathrm{~mL}$ of $\mathrm{NaClO}$ solution $(0.05 \mathrm{M})$ and $0.2 \mathrm{~mL}$ of sodium nitroferricyanide solution ( $1 \mathrm{wt} \%$ ) were added subsequently. After $2 \mathrm{~h}$, the absorption spectra of the resulting solution were acquired with an ultraviolet-visible (UV-vis) spectrophotometer (BioTek Synergy H1 Hybrid Multi-Mode Reader). The formed indophenol blue was measured by absorbance at $\lambda=653 \mathrm{~nm}$. In order to quantify the produced $\mathrm{NH}_{3}$, the calibration curves were built using standard $\mathrm{NH}_{4} \mathrm{Cl}$ solutions in the presence of $0.05 \mathrm{M} \mathrm{H}_{2} \mathrm{SO}_{4}, 0.1 \mathrm{M} \mathrm{PBS}$, and $0.1 \mathrm{M} \mathrm{NaOH}$, respectively (Supplementary Fig. 4), to take into account the possible influence of different $\mathrm{pH}$ values ${ }^{38}$. The measurements with the background solutions $\left(\right.$ no $\left.\mathrm{NH}_{3}\right)$ were performed for all experiments, and the background peak was subtracted from the measured peaks of $\mathrm{N}_{2} \mathrm{RR}$ experiments to calculate the $\mathrm{NH}_{3}$ concentrations and the Faradaic efficiencies.

Hydrazine quantification. The yellow color developed upon the addition of $p$ dimethylaminobenzaldehyde (PDAB) to solutions of $\mathrm{N}_{2} \mathrm{H}_{4}$ in dilute hydrochloric acid solution was used as the basis for the spectrophotometric method to quantify the $\mathrm{N}_{2} \mathrm{H}_{4}$ concentration ${ }^{39}$. Typically, $5 \mathrm{~mL}$ of the electrolyte solution was taken out and then mixed with $5 \mathrm{~mL}$ of the coloring solution $(4 \mathrm{~g}$ of PDAB dissolved in 20 $\mathrm{mL}$ of concentrated hydrochloric acid and $200 \mathrm{~mL}$ of ethanol). After $15 \mathrm{~min}$, the absorption spectra of the resulting solution were acquired using a UV-vis spectrophotometer (BioTek Synergy H1 Hybrid Multi-Mode Reader). The solutions of $\mathrm{N}_{2} \mathrm{H}_{4}$ with known concentrations in 0.1 M PBS were used as calibration standards, and the absorbance at $\lambda=458 \mathrm{~nm}$ was used to plot the calibration curves (Supplementary Fig. 5).

Calculation of the equilibrium potential. The standard potential for the half reaction of $\mathrm{N}_{2}$ reduction to $\mathrm{NH}_{4} \mathrm{OH}$ was calculated according to the standard molar Gibbs energy of formation at $298.15 \mathrm{~K}^{49}$. The equilibrium potential under our experimental conditions is calculated using the Nernst equation, assuming 1 atm of $\mathrm{N}_{2}$ and a $\mathrm{NH}_{4} \mathrm{OH}$ concentration of $0.01 \mathrm{mM}$ in the solution.

$$
\mathrm{N}_{2}(\mathrm{~g})+2 \mathrm{H}_{2} \mathrm{O}+6 \mathrm{H}^{+}+6 \mathrm{e}^{-} \rightarrow 2 \mathrm{NH}_{4} \mathrm{OH}(\mathrm{aq}) \quad \Delta G^{\circ}=-33.8 \mathrm{~kJ} \mathrm{~mol}^{-1}
$$

$E^{\circ}=-\Delta G^{\circ} / n F=0.058 \mathrm{~V}$, where $n=6$ is the number of electrons transferred in the reaction and $F$ is the Faraday constant.

The equilibrium potential under our experimental conditions is calculated using the Nernst equation, assuming $1 \mathrm{~atm}$ of $\mathrm{N}_{2}$ and a $0.01 \mathrm{mM}$ concentration of $\mathrm{NH}_{4} \mathrm{OH}$ in the solution.

$$
E=E^{\circ}-\frac{R T}{6 F} \ln \left(\frac{\left[\mathrm{NH}_{4} \mathrm{OH}\right]^{2}}{\left[\mathrm{H}^{+}\right]^{6}}\right)+0.059 \mathrm{~V} \times \mathrm{pH}=0.156 \mathrm{~V} \text { vs. RHE }
$$

Calculation of the Faradaic efficiency and the yield rate. The Faradaic efficiency was estimated from the charge consumed for $\mathrm{NH}_{3}$ production and the total charge passed through the electrode:

$$
\text { Faradaic efficiency }=\left(3 F \times c_{\mathrm{NH}_{3}} \times V\right) / Q
$$

The yield rate of $\mathrm{NH}_{3}$ can be calculated as follows:

$$
\text { Yield rate }=\left(17 c_{\mathrm{NH}_{3}} \times V\right) /(t \times m)
$$

where $F$ is the Faraday constant $\left(96,485 \mathrm{C} \mathrm{mol}^{-1}\right), c_{\mathrm{NH}_{3}}$ is the measured $\mathrm{NH}_{3}$ concentration, $V$ is the volume of the electrolyte, $Q$ is the total charge passed through the electrode, $t$ is the electrolysis time $(3 \mathrm{~h})$, and $m$ is the metal mass of the catalyst (typically $0.3 \mathrm{mg}$ ). The reported $\mathrm{NH}_{3}$ yield rate, Faradaic efficiency, and error bars were determined based on the measurements of three separately prepared samples under the same conditions.

${ }^{15} \mathbf{N}$ isotope labeling experiment. The isotopic labeling experiment was carried out using ${ }^{15} \mathrm{~N}_{2}$ as the feeding gas (Sigma-Aldrich, 98 atom $\%{ }^{15} \mathrm{~N}$ ) with $0.1 \mathrm{M}$ PBS electrolyte. After electrolysis at $-0.05 \mathrm{~V}$ vs. RHE for $10 \mathrm{~h}, 10 \mathrm{~mL}$ of the electrolyte was taken out and acidized to $\mathrm{pH} \sim 3$ by adding $0.5 \mathrm{M} \mathrm{H}_{2} \mathrm{SO}_{4}$, and then concentrated to $2 \mathrm{~mL}$ by heating at $70^{\circ} \mathrm{C}$. Afterwards, $0.9 \mathrm{~mL}$ of the resulting solution was taken out and mixed with $0.1 \mathrm{~mL} \mathrm{D}_{2} \mathrm{O}$ containing $100 \mathrm{ppm}$ dimethyl sulphoxide (Sigma-Aldrich, 99.99\%) as an internal standard for ${ }^{1} \mathrm{H}$ nuclear magnetic resonance measurement ( ${ }^{1} \mathrm{H}$ NMR, Bruker Avance III $\left.400 \mathrm{MHz}\right)$.

Computational studies. DFT calculations were performed using the plane-wavebased PWSCF (Quantum-ESPRESSO) program and the Atomic Simulation Environment (ASE). The ultrasoft Vanderbilt pseudopotential method with Perdew-Burke-Ernzerhof (PBE) exchange-correlation functional was adopted. More calculation details and relevant references are provided in the Supplementary Note 1, Supplementary Table 2, and Supplementary References.

Data availability. The data that support the findings of this study are available within the paper and its Supplementary Information file or are available from the corresponding authors upon reasonable request.

Received: 20 December 2017 Accepted: 11 April 2018

Published online: 15 May 2018

\section{References}

1. Chu, S. \& Majumdar, A. Opportunities and challenges for a sustainable energy future. Nature 488, 294-303 (2012).

2. Smil, V. Enriching the Earth: Fritz Haber, Carl Bosch, and the Transformation of World Food Production (MIT Press, Cambridge, 2004).

3. Jennings, J. R. Catalytic Ammonia Synthesis: Fundamentals and Practice (Springer Science \& Business Media, New York, 2013).

4. Gruber, N. \& Galloway, J. N. An Earth-system perspective of the global nitrogen cycle. Nature 451, 293-296 (2008).

5. Erisman, J. W., Sutton, M. A., Galloway, J., Klimont, Z. \& Winiwarter, W. How a century of ammonia synthesis changed the world. Nat. Geosci. 1, 636-639 (2008)

6. Apodaca, L. E. In Mineral Commodity Summaries 2016: U.S. Geological Survey (ed. Kimball, S. M.) 118-119 (Government Publishing Office, Washington, DC, 2016).

7. Kitano, M. et al. Ammonia synthesis using a stable electride as an electron donor and reversible hydrogen store. Nat. Chem. 4, 934-940 (2012).

8. Service, R. F. New recipe produces ammonia from air, water, and sunlight. Science 345, 610 (2014).

9. van der Ham, C. J. M., Koper, M. T. M. \& Hetterscheid, D. G. H. Challenges in reduction of dinitrogen by proton and electron transfer. Chem. Soc. Rev. 43, 5183-5191 (2014)

10. Ali, M. et al. Nanostructured photoelectrochemical solar cell for nitrogen reduction using plasmon-enhanced black silicon. Nat. Commun. 7, 11335 (2016).

11. Brown, K. A. et al. Light-driven dinitrogen reduction catalyzed by a CdS: nitrogenase MoFe protein biohybrid. Science 352, 448-450 (2016).

12. Rosca, V., Duca, M., de Groot, M. T. \& Koper, M. T. M. Nitrogen cycle electrocatalysis. Chem. Rev. 109, 2209-2244 (2009).

13. Renner, J. N., Greenlee, L. F., Ayres, K. E. \& Herring, A. M. Electrochemical synthesis of ammonia: a low pressure, low temperature approach. Electrochem. Soc. Interface 24, 51-57 (2015).

14. Kyriakou, V., Garagounis, I., Vasileiou, E., Vourros, A. \& Stoukides, M. Progress in the electrochemical synthesis of ammonia. Catal. Today 286, 2-13 (2017).

15. Shipman, M. A. \& Symes, M. D. Recent progress towards the electrosynthesis of ammonia from sustainable resources. Catal. Today 286, 57-68 (2017).

16. Zamfirescu, C. \& Dincer, I. Using ammonia as a sustainable fuel. J. Power Sources 185, 459-465 (2008).

17. Klerke, A., Christensen, C. H., Nørskov, J. K. \& Vegge, T. Ammonia for hydrogen storage: challenges and opportunities. J. Mater. Chem. 18, 2304-2310 (2008).

18. Soloveichik, G. Liquid fuel cells. Beilstein J. Nanotechnol. 5, 1399-1418 (2014).

19. Licht, $\mathrm{S}$. et al. Ammonia synthesis by $\mathrm{N}_{2}$ and steam electrolysis in molten hydroxide suspensions of nanoscale $\mathrm{Fe}_{2} \mathrm{O}_{3}$. Science 345, 637-640 (2014). 
20. Bao, D. et al. Electrochemical reduction of $\mathrm{N}_{2}$ under ambient conditions for artificial $\mathrm{N}_{2}$ fixation and renewable energy storage using $\mathrm{N}_{2} / \mathrm{NH}_{3}$ Cycle. $A d v$. Mater. 29, 1604799 (2017).

21. Shi, M. M. et al. Au sub-nanoclusters on $\mathrm{TiO}_{2}$ toward highly efficient and selective electrocatalyst for $\mathrm{N}_{2}$ conversion to $\mathrm{NH}_{3}$ at ambient conditions. $A d v$. Mater. 29, 1606550 (2017).

22. Li, S. J. et al. Amorphizing of Au nanoparticles by $\mathrm{CeO}_{\mathrm{x}}-\mathrm{RGO}$ hybrid support towards highly efficient electrocatalyst for $\mathrm{N}_{2}$ reduction under ambient conditions. Adv. Mater. 29, 1700001 (2017).

23. Ma, J. L., Bao, D., Shi, M. M., Yan, J. M. \& Zhang, X. B. Reversible nitrogen fixation based on a rechargeable lithium-nitrogen battery for energy storage. Chem 2, 525-532 (2017).

24. McEnaney, J. M. et al. Ammonia synthesis from $\mathrm{N}_{2}$ and $\mathrm{H}_{2} \mathrm{O}$ using a lithium cycling electrification strategy at atmospheric pressure. Energy Environ. Sci. 10, 1621-1630 (2017).

25. Chen, G. F. et al. Ammonia electrosynthesis with high selectivity under ambient conditions via a $\mathrm{Li}^{+}$incorporation strategy. J. Am. Chem. Soc. 139, 9771-9774 (2017).

26. Kordali, V., Kyriacou, G. \& Lambrou, C. Electrochemical synthesis of ammonia at atmospheric pressure and low temperature in a solid polymer electrolyte cell. Chem. Commun. (https://doi.org/10.1039/B004885M (2000).

27. Giddey, S., Badwal, S. P. S. \& Kulkarni, A. Review of electrochemical ammonia production technologies and materials. Int. J. Hydrog. Energy 38, 14576-14594 (2013).

28. Lan, R., Irvine, J. T. S. \& Tao, S. Synthesis of ammonia directly from air and water at ambient temperature and pressure. Sci. Rep. 3, 1145 (2013).

29. Kim, K. et al. Electrochemical reduction of nitrogen to ammonia in 2propanol under ambient temperature and pressure. J. Electrochem. Soc. 163, F610-F612 (2016).

30. Chen, S. et al. Electrocatalytic synthesis of ammonia at room temperature and atmospheric pressure from water and nitrogen on a carbon-nanotube-based electrocatalyst. Angew. Chem. Int. Ed. 56, 2699-2703 (2017).

31. Nash, J. et al. Electrochemical nitrogen reduction reaction on noble metal catalysts in proton and hydroxide exchange membrane electrolyzers. J. Electrochem. Soc. 164, F1712-F1716 (2017)

32. Montoya, J. H., Tsai, C., Vojvodic, A. \& Nørskov, J. K. The challenge of electrochemical ammonia synthesis: a new perspective on the role of nitrogen scaling relations. ChemSusChem 8, 2180-2186 (2015)

33. Singh, A. R. et al. Electrochemical ammonia synthesis-the selectivity challenge. ACS Catal. 7, 706-709 (2017)

34. Zhu, D., Zhang, L., Ruther, R. E. \& Hamers, R. J. Photo-illuminated diamond as a solid-state source of solvated electrons in water for nitrogen reduction. Nat. Mater. 12, 836-841 (2013).

35. Akagi, F., Matsuo, T. \& Kawaguchi, H. Dinitrogen cleavage by a diniobium tetrahydride complex: formation of a nitride and its conversion into imide species. Angew. Chem. Int. Ed. 46, 8778-8781 (2007).

36. Shima, T. et al. Dinitrogen cleavage and hydrogenation by a trinuclear titanium polyhydride complex. Science 340, 1549-1552 (2013).

37. Wang, P. et al. Breaking scaling relations to achieve low-temperature ammonia synthesis through $\mathrm{LiH}$-mediated nitrogen transfer and hydrogenation. Nat. Chem. 9, 64-70 (2017).

38. Searle, P. L. The berthelot or indophenol reaction and its use in the analytical chemistry of nitrogen. A review. Analyst 109, 549-568 (1984).

39. Watt, G. W. \& Chrisp, J. D. A spectrophotometric method for the determination of hydrazine. Anal. Chem. 24, 2006-2008 (1952).
40. Strmcnik, D., Lopes, P. P., Genorio, B., Stamenkovic, V. R. \& Markovic, N. M. Design principles for hydrogen evolution reaction catalyst materials. Nano Energy 29, 29-36 (2016).

41. Wickman, B. et al. Depth probing of the hydride formation process in thin $\mathrm{Pd}$ films by combined electrochemistry and fiber optics-based in situ UV/vis spectroscopy. Phys. Chem. Chem. Phys. 17, 18953-18960 (2015).

42. Hara, M., Linke, U. \& Wandlowski, T. Preparation and electrochemical characterization of palladium single crystal electrodes in $0.1 \mathrm{M} \mathrm{H}_{2} \mathrm{SO}_{4}$ and $\mathrm{HClO}_{4}$ : Part I. Low-index phases. Electrochim. Acta 52, 5733-5748 (2007)

43. Min, X. \& Kanan, M. W. Pd-catalyzed electrohydrogenation of carbon dioxide to formate: high mass activity at low overpotential and identification of the deactivation pathway. J. Am. Chem. Soc. 137, 4701-4708 (2015).

44. Klinkova, A. et al. Rational design of efficient palladium catalysts for electroreduction of carbon dioxide to formate. ACS Catal. 6, 8115-8120 (2016).

45. Gao, D. F. et al. Switchable $\mathrm{CO}_{2}$ electroreduction via engineering active phases of Pd nanoparticles. Nano Res. 10, 2181-2191 (2017).

46. Honkala, K. et al. Ammonia synthesis from first-principles calculations. Science 307, 555-558 (2005)

47. Hinnemann, B. et al. Biomimetic hydrogen evolution: $\mathrm{MoS}_{2}$ nanoparticles as catalyst for hydrogen evolution. J. Am. Chem. Soc. 127, 5308-5309 (2005).

48. Agmon, N. The Grotthuss mechanism. Chem. Phys. Lett. 244, 456-462 (1995)

49. Rumble, J. CRC Handbook of Chemistry and Physics 98th edn (CRC Press, Boca Raton, FL, 2017).

\section{Acknowledgements}

This work is supported by the Startup Fund from the University of Central Florida (UCF). X.F. is a member of the Energy Conversion and Propulsion Cluster at UCF. J.W. gratefully acknowledges the Preeminent Postdoctoral Program (P3) award from UCF. L. Y. and H.X. acknowledge the financial support from the American Chemical Society Petroleum Research Fund (ACS PRF 55581-DNI5) and the NSF CBET Catalysis Program (CBET-1604984).

\section{Author contributions}

J.W. and X.F. conceived and designed the experiments. J.W. synthesized the materials and carried out the experimental work. L.Y. and H.X. performed the computational work. L.H. assisted in the experimental work. G.C. contributed to $\mathrm{NH}_{3}$ quantification. X. F. and H.X. co-wrote the manuscript. All authors discussed the results and commented on the manuscript.

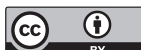

Open Access This article is licensed under a Creative Commons Attribution 4.0 International License, which permits use, sharing, adaptation, distribution and reproduction in any medium or format, as long as you give appropriate credit to the original author(s) and the source, provide a link to the Creative Commons license, and indicate if changes were made. The images or other third party material in this article are included in the article's Creative Commons license, unless indicated otherwise in a credit line to the material. If material is not included in the article's Creative Commons license and your intended use is not permitted by statutory regulation or exceeds the permitted use, you will need to obtain permission directly from the copyright holder. To view a copy of this license, visit http://creativecommons.org/ licenses/by/4.0/.

(C) The Author(s) 2018 